http://jmscr.igmpublication.org/home/ ISSN (e)-2347-176x ISSN (p) 2455-0450 crossref DOI: https://dx.doi.org/10.18535/jmscr/v9i6.16

\title{
Functional Outcome of Colles Fracture \& Colles Fracture With Ulnar Styloid Fracture- A Comparative Study
}

\author{
Authors \\ Dr Praveen Kumar. TS ${ }^{1}$, Dr Jagajeev. $\mathbf{J R}^{2^{*}}$, Dr Shibu. ${ }^{3}$, Dr Sabarisree $\mathbf{M}^{\mathbf{4}}$ \\ ${ }^{1}$ Post graduate Student in Orthopaedics, Govt. Medical College Hospital, Thiruvananthapuram \\ ${ }^{2}$ Addl. Professor, Dept of Orthopaedics, Govt Medical College Hospital, Thiruvananthapuram \\ ${ }^{3}$ Asst. Professor, Dept. of Orthopaedics, Govt. medical college Hospital, Thiruvananthapuram \\ ${ }^{4}$ Addl. Professor, Dept of Orthopaedics, Govt Medical College Hospital, Thiruvananthapuram \\ *Corresponding Author \\ Dr Jagajeev. JR \\ Addl. Professor, Dept of Orthopaedics, Govt. Medical College Hospital, Thiruvananthapuram
}

\begin{abstract}
Objectives: To compare the functional outcome of colles fracture \& colles fracture with ulnar styloid fracture, managed conservatively by closed manipulation and cast immobilization

Methods: Prospective observational study. Total sample size was 100.Patients were divided into two groups.50 patients in each group were studied. Group I as those with colles fracture alone and group II as those with combined colles and ulnar styloid fracture.

Results: In both groups initial radiographic findings were noted and statistically significant difference was found between palmar tilt of both groups and the P value is 0.003 . Nostatistical difference between dorsal angulation, radial inclination and radial length noted

Conclusion: We conclude that presence of an associated ulnar styloid fracture in a colles fracture results in poor functional status and reduced range of movements in a significant number of patients and these fractures should be taken more seriously and managed effectively.
\end{abstract}

\section{Introduction}

Distal radius fractures are one of the most common injuries encountered in orthopaedic practice. They makeup $8-15 \%$ of all bony injuries in adults. Colles fracture specifically is defined as metaphyseal injury of cortico cancellous junction (within 2-3 cm of articular surface) of the distal radius. Ulnar styloid fractures are common associated injuries in patients with colles fracture. Their role in the functional outcome of these fractures however is unclear.

\section{Aims and Objectives}

To compare the functional outcome of colles fracture \& colles fracture with ulnar styloid fracture, managed conservatively by closed manipulation and cast immobilization

\section{Review of Literature}

Irish surgeon Sir Abraham colles before invention of radiography, made a brief accurate description of about the distal radial fractures based on the just the clinical examination. 
John Rhea Barton (1794-1871) orthopaedic surgeon worked In Pennsylvania Hospital in Philadelphia (USA) described about the fractures with intra articular involvement that was later termed as volar and dorsal barton fractures.

Robert William Smith (1807-1873) Irish surgeon described about the smith fractures. In 1967, Frykman identified the importance of ulnar involvement and published a classification based on involvement of radio carpal and radioulnar joints and the ulnar styloid fragments.

In 1993, Fernandez classification was introduced which was designed to be practical, determine stability, include associated injuries and provide general treatment recommendations.

External fixation was first described by Andersnand O’Neil.

\section{Anatomy- Triangular fibrocartilage (Components of TFCC)}

1. Cartilaginous articular disc

2. The meniscal homologue

3. Radio ulnar interconnecting ligaments

4. Floor of extensor carpi ulnaris subsheath

5. Ulnolunate

6. Ulnar collateral

7. Ulno triquetral ligament

TFCC is the main stabilizer of distal radio ulnar joint and plays an important role in load sharing. During axial loading, radius transmits $82 \%$ load and ulna carries only $18 \%$ but in positive ulnar variance load transmission across TFCC increases to $42 \%$ because TFCC extends the distal radius joint surface to cover.

The articular disk (triangular fibrocartilage)- the articular disk is triangular shaped, located transversely, maintains the distal ends of the ulna and radius close together.

Three column model of the wrist joint- The 3 column model of the distal forearm is a simple concept that aids understanding some distal radial fracture pattern and in planning internal fixation.

1. The radial column comprise the radial styloid process and with the lateral scaphoid fossa
2. The intermediate column contains the middle lunate fossa and the ulnar notch medially

3. The ulnar column is made by the distal radioulnar joint, the ulnar styloid process and the triangular fibro cartilage complex.

The major load was transmitted across the intermediate lunate fossa columns and a little by the radial column of scaphoid fossa. This pressure area is shifted when the wrist brought into extension.

Less than $5 \mathrm{~mm}$ shortening when compared to the contralateral wrist is accepted with good functional scores. More than $10 \mathrm{~mm}$ shortening indicates radial head fracture.

The acceptable reduction of radial inclination is more than 15 degree. Any decrease in the radial inclination will produce more axial and compressive load to be transmitted along the lunate facet and may lead to secondary post traumatic osteoarthritis and decreased ulnar deviation of wrist.

Palmar or volar tilt normally ranges from neutral to 25 degree and the mean is 12 degree. Any dorsal angulation up to 10 degrees is accepted and the patient becomes symptomatic if the angulation exceeds this level. Disturbances in the palmar tilt may lead to decreased hand grip strength.

Acceptable level in these radiological parameters for healed radius fracture are

1. Radial length - within $2-3 \mathrm{~mm}$ of the contralateral wrist.

2. Palmar tilt - neutral tilt (0 degree)

3. Intraarticular step off $<2 \mathrm{~mm}$

4. Radial angle $<5$ degree loss

5. Carpal malalignment absent

\section{Mechanism of Injury}

Fall on outstretched hand is the most common mechanism leading to distal radius fracture. The fracture pattern is determined by the following variables.

- Velocity of injury

- Quality of bone

- Position of wrist, forearm and hand. 
Colles fracture-When the forearm is pronated and when the person falls with hyperextended radially deviated wrist compression forces are transmitted along to weak cancellous metaphyseal bone producing tensile volar cortex and compressible dorsal cortex to be fractured. Fall over pronated wrist produces typical dorsal displacement and angulation. More severe compressive stress produces intraarticular fractures.

\section{Materials and Methods}

Study Design: Prospective observational study

Study Setting: Orthopaedics OPD and casualty, Government Medical College, Trivandrum

Study Population: All patients with colles fracture alone and colles fracture with ulnar styloid fracture presenting to department of orthopaedics Govt: Medical College, Trivandrum.

Study Period: December 2019 to November 2020.

Study Method: Total sample size was 100.Patients were divided into two groups.50 patients in each group were studied. Group I as those with colles fracture alone and group II as those with combined colles and ulnar styloid fracture.

Both groups of patients were assessed with mayo wrist score, and comparative analysis of functional status of two groups were done. The patients were reviewed on four, eight, twelve and twenty fourth weeks, functional outcome was made from final follow up at twenty fourth week. The patients were initially observed radiologically for the type of fracture, degrees of dorsal angulation, dorsal metaphyseal comminution, intraarticular involvement, radial length, palmar tilt and radial inclinations. All the patients were treated with closed manipulative reduction and immobilized in a dorso -radial above elbow or below elbow plaster. Post reduction radiological evaluation was done for radial length, palmar tilt and radial inclination.

Cast was removed once there was union, for most of the patients cast was removed at 6 weeks.
Patients were reviewed at $8,12,24$ weeks of treatment. Every time functional and radiological outcome was made and compared to normal side. Functional outcome was assessed using Modified Mayo wrist score.

\begin{tabular}{lc} 
Pain & Point \\
No pain & 25 \\
Mild occasional & 20 \\
Moderate & 15 \\
Severe & 0 \\
& \\
Work status & 25 \\
Regular job & 20 \\
Restricted job & 15 \\
Able to work but unemployed & 0 \\
Unable to work due to pain & \\
& 25 \\
Range of motion & 25 \\
$>120^{\circ}$ & 20 \\
100 to $119^{\circ}$ & 15 \\
90 to $99^{\circ}$ & 10 \\
60 to $89^{\circ}$ & 5 \\
30 to $59^{\circ}$ & 0 \\
0 to $29^{\circ}$ & \\
Grip strength (\% of normal) & 25 \\
90 to 100 & 15 \\
75 to 89 & 10 \\
50 to 74 & 5 \\
25 to 49 & 0 \\
0 to 24 & \\
\hline
\end{tabular}

* Total point scores: excellent (91 to 100), good (80 to 90), fair $(65$ to 79$)$, and poor $(<64)$.

\section{Modified Mayo wrist score.}

\section{Interpretations}

- Score between 90 to 100 are considered excellent

- Score between 80 to 89 are considered good

- Score between 65 to 79 are considered as fair

- Score less than 65 are considered as poor. 


\section{Results and Analysis}

Table-1 Gender Distribution

\begin{tabular}{|l|c|c|}
\hline & GROUP I & GROUP II \\
\hline MALE & 14 & 9 \\
\hline FEMALE & 36 & 41 \\
\hline SUM & 50 & 50 \\
\hline TOTAL & 100 & \\
\hline
\end{tabular}

\section{Table-2}

No statistically significant differences based on gender between 2 groups, using chi square test

\begin{tabular}{|l|c|c|c|c|}
\hline & \multicolumn{2}{|c|}{ GROUP I } & GROUP II \\
\hline & FREQUENCY & PERCENTAGE & FREQUENCY & PERCENTAGE \\
\hline FEMALE & 36 & $72.0 \%$ & 41 & $82.0 \%$ \\
\hline MALE & 14 & $28 / 0 \%$ & 9 & $18.0 \%$ \\
\hline TOTAL & 50 & $100 \%$ & 50 & $100 \%$ \\
\hline
\end{tabular}

Pearson Chi square t-1.42 P value-0.235

Table-3 Age Distribution

\begin{tabular}{|l|c|c|c|c|}
\hline \multicolumn{3}{|c|}{ GROUP I } & GROUP II \\
\hline & MALE & FEMALE & MALE & FEMALE \\
\hline $40-49$ & 1 & 3 & 1 & 2 \\
\hline & & & & \\
\hline $50-59$ & 10 & 21 & 7 & 20 \\
\hline $60-70$ & 3 & 12 & 1 & 19 \\
\hline TOTAL & 14 & 36 & 9 & 41 \\
\hline
\end{tabular}

Table-4 Side of Injury

\begin{tabular}{|l|c|c|}
\hline & GROUP I & GROUP 2 \\
\hline LEFT & 15 & 18 \\
\hline RIGHT & 35 & 32 \\
\hline
\end{tabular}

Table-5 Mode of Injury

\begin{tabular}{|l|c|c|}
\hline & GROUP I & GROUP 2 \\
\hline FALL & 47 & 44 \\
\hline RTA & 3 & 6 \\
\hline
\end{tabular}

Independent sample $\mathrm{t}$ test showed no statistically difference between the mean ages of two groups

\begin{tabular}{|l|c|c|c|}
\hline GROUPS & MEAN (SD) & t STATISTIC & P VALUE \\
\cline { 1 - 2 } GROUP 1 & $56.25(5.8)$ & -1.667 & 0.099 \\
\cline { 1 - 2 } GROUP 2 & $58.42(5.6)$ & & \\
\hline
\end{tabular}

Table-6 Functional Outcome Score

\begin{tabular}{|l|c|c|}
\hline & GROUP I & GROUP 2 \\
\hline EXCELLENT & 30 & 21 \\
\hline GOOD & 12 & 8 \\
\hline FAIR & 3 & 9 \\
\hline POOR & 5 & 12 \\
\hline
\end{tabular}


Table-7 Functional Out Come Score

\begin{tabular}{|l|c|c|c|c|c|}
\hline & & \multicolumn{2}{|c|}{ GROUP I } & GROUP II \\
\hline & & FREQUENCY & PERCENTAGE & FREQUENCY & PERCENTAGE \\
\hline EXCELLENT & & 30 & 60 & 21 & 42 \\
\hline GOOD & & 12 & 24 & 8 & 16 \\
\hline FAIR & & 3 & 6 & 9 & 18 \\
\hline POOR & & 5 & 10 & 12 & 24 \\
\hline TOTAL & & 50 & $100 \%$ & 50 & $100 \%$ \\
\hline
\end{tabular}

Statistically significant difference is noted between functional outcomes of both groups.

Pearson Chi-square $-8.271 \mathrm{p}$ value -0.041

Table-8 Pain

\begin{tabular}{|l|c|c|}
\hline & GROUP I & GROUP 2 \\
\hline NO PAIN & 41 & 36 \\
\hline MILD & 7 & 7 \\
\hline MODERATE & 2 & 7 \\
\hline SEVERE & 0 & 0 \\
\hline
\end{tabular}

Table-9 Functional Status

\begin{tabular}{|l|c|c|}
\hline & GROUP I & GROUP 2 \\
\hline REGULAR & 24 & 14 \\
\hline RESTRICTED & 17 & 18 \\
\hline ABLE TO WORK & 9 & 18 \\
\hline UNABLE TO WORK & 0 & 0 \\
\hline
\end{tabular}

Table-10 Range of Movements

\begin{tabular}{|l|c|c|}
\hline & GROUP I & GROUP 2 \\
\hline$>120(25)$ & 11 & 7 \\
\hline $100-119(20)$ & 22 & 17 \\
\hline $90-99(15)$ & 11 & 14 \\
\hline $60-89(10)$ & 6 & 12 \\
\hline $30-59(5)$ & 0 & 0 \\
\hline$<30$ & 0 & 0 \\
\hline
\end{tabular}

Table-11 Grip Strength

\begin{tabular}{|l|c|c|}
\hline & GROUP I & GROUP 2 \\
\hline $90-100(25)$ & 38 & 30 \\
\hline $75-89(15)$ & 9 & 14 \\
\hline $50-74(10)$ & 3 & 6 \\
\hline $25-49(5)$ & 0 & 0 \\
\hline$<25(0)$ & 0 & 0 \\
\hline
\end{tabular}

Mann-Whitney Test done to find if any significant difference between the Mayo total score, functional status score, ROM score, grip strength score, dorsalangulation, palmartilt, radial inclination and radial length values of the two groups. Mann-Whitney u test was used because the variables examined (score) did not follow normality assumptions. In both groups initial radiographic findings were noted and statistically significant difference was found between palmar tilt of both groups and the $\mathrm{P}$ value is 0.003 . No statistical difference between dorsal angulation, radial inclination and radial length noted.

Mean dorsal angulation in group I is $14.96 \pm 4.9$ and in group II15.19 \pm 4.41

Mean palmar tilt in group I is $14.68 \pm$ and in group II $13.08 \pm 3.09$

Mean radial inclination in group $\mathrm{I}$ is $20.68 \pm 2.62$ and in groupII $20.3 \pm 2.54$

Mean radial length in group $\mathrm{I}$ is $10.52 \pm 1.44$ and in group II $10.42 \pm 1.51$ 


\section{Discussion}

Ulnar styloid fractures accompany $51 \%$ to $65 \%$ of distal radius fractures and represent important factor that may affect outcome. Oskarsson et al. ${ }^{8}$ in a case series of 158 fractures found great degree of loss of mobility and grip strength in patients with styloid process fracture treated surgically and concluded that styloid process to be great predictor of fracture instability than articular involvement. Although there is literature supporting both surgical as well as nonsurgical treatment of styloid process fracture, we believe the individual assessment of fracture is very important as all patients with styliod process fracture do not develop DRUJ instability. In 1985, Stewart et.al reviewed the outcomes of 235 patients with extra-articular distal radius fractures, and did not find a correlation between ulnar styloid fracture and function. In 1967, Frykman suggested that fractures of the ulnar styloid substantially affect the outcomes of distal radius fractures, and he included the ulnar styloid in his distal radius fracture classification system. In 1988, Kaukonen Et.al reported a series of 207 consecutive patients with distal radius fractures treated both surgically and nonsurgically andconcluded that fractures of the ulnar styloid contributed to poor results. In 1997, Oskarsson et al. evaluated 158 patients with Colles' fracture treated with cast immobilization and found that a fracture of the ulnar styloid was a more important predictor of fracture stability and functional outcome than was articular

Imtiyaz Hussain Dar et al. ${ }^{2}$. Retrospectively evaluated 150 patients in 2015 and they found that presence of a fracture of ulnar styloid process with distal radius fracture results in a weak and painful wrist in a significant number of patients.

Functional outcome were assessed with modified mayo wrist score in two groups and the outcome were compared. Statistically significant difference is found between the two groups and $p$ value by Pearson Chi square is 0.041. Based on our study, significant difference is there in the functional outcome of colles fracture alone and colles fracture with ulnar styloid fracture. Patients with colles fracture alone is having a better outcome than those with associated ulnar styloid fracture.

\section{Conclusion}

We conclude that presence of an associated ulnar styloid fracture in a colles fracture results in poor functional status and reduced range of movements in a significant number of patients and these fractures should be taken more seriously and managed effectively. However further studies need to done especially randomized trials and meta-analysis to reach to consensus in such a controversial subject.

\section{References}

1. Rayhack JM. The history and evolution of percutaneous pinning of displaced distal radius fractures. Orthop Clin North Am 1993;24: 287-300.

2. Effect of ulnar styloid fracture on functional outcome of Colles fractures: a comparative analysis of two groups Imtiyaz Hussain Dar 1, Iftikhar H. Wani 1 *, Ummar Mumtaz 1, MasratJan page 1 International Surgery Journal | October December 2015| Vol 2 | Issue 4 Page 556 International Surgery Journal Dar IH et al. Int Surg J. 2015 Nov;2(4): 556-559

3. Frykman G. Fracture of the distal radius including sequelae-shoulder-hand-finger syndrome, disturbance in the distal radioulnar joint and impairment of nerve function. A clinical and experimental study. Acta orthopScand1967;Suppl 108:1-155

4. Oskarsson GV, Aaser P, Hjall A. Do we underestimate the predictive value of the ulnar styloid affection in Colles fractures? Arch Orthop Trauma Surg 1997;116:34134

5. Melone CP, Nathan $\mathrm{R}$.Traumatic disruption of triangular fibrocartilage complex. Clin Orthop.1992; 275:65-73 
6. Landau T, Hagberg L, Adlercreutz C, Jonson K, Aspenberg P. Distal radioulnar instability is an independent worsening factor in distal radial fractures. Clin OrthopRelat Res 2000; 376:229-235.

7. Hauck RM, Skahen J III, Palmer AK, classification and treatment of ulnar styloid nonunion. J Hand Surg 1996;21A:418-422

8. Short WH, Palmer AK, Werner FW, Et al: A biomechanical study of distal radial fractures, J Hand Surg (Am) 12:529-534, 1987.

9. Kreder HJ, Hanel DP, McKee M, et al : Consistency of AO fracture classification of the distal radius, $\mathrm{J}$ Bone Surg $\mathrm{Br}$ 78:726-731, 1996.

10. Medoff RJ: Essential radiographic evaluation of distal radius fractures, Hand clin 21:279-288, 2005. 